\title{
New species of Paratanytarsus Thienemann \& Bause 1913 (Diptera: Chironomidae) from the Mediterranean Region (Corsica, southern France and Lebanon)
}

\author{
Joel Moubayed-Breil', Patrick Ashe ${ }^{2}$ and Peter H. Langton ${ }^{3}$
}

\begin{abstract}
Moubayed-Breil J, Ashe P and Langton PH. 2012. New species of Paratanytarsus Thienemann \& Bause 1913 (Diptera: Chironomidae) from the Mediterranean Region (Corsica, southern France and Lebanon). Fauna norvegica 31: 183-194.
\end{abstract}

\begin{abstract}
Three new species of Paratanytarsus are described, from Corsica, southern France and Lebanon, based on the adult males and associated pupal exuviae. These descriptions increase the number of western Palaearctic species in the genus to 23. The pupal exuviae of the new species resemble those of $P$. bituberculatus (Edwards). Main diagnostic characters as well as additional illustrations of $P$. bituberculatus are also presented. Characters are given for distinguishing the adult males and the pupal exuviae from other related species. A key to the adult males and pupal exuviae of the described species is provided.
\end{abstract}

doi: 10.5324/fn.v31i0.1372. Received: 2011-10-14. Accepted: 2012-07-16.

Published on paper and online: 2012-10-17.

Keywords: Diptera-Chironomidae, Paratanytarsus, new species, Mediterranean Region

1. Applied ecology, 10 rue des Fenouils, F-34070 Montpellier, France

2. 33 Shelton Drive, Terenure, Dublin 12, Ireland

3. 16 Irish Society Court, Coleraine, Co. Londonderry, BT52 1GX Northern Ireland

Corresponding author: Joel Moubayed-Breil

E-mail:jm.aquabiol@neuf.fr

\section{INTRODUCTION}

Worldwide there are currently about 45 valid species of Paratanytarsus Thienemann \& Bause, which are reported from all zoogeographical regions except the Afrotropical and Antarctica. In the western Palaearctic (Europe, North Africa and the Middle East) there are 20 species in the genus. A partial taxonomic study and revision of the genus, covering most of the Palaearctic region (except Japan), was published by Shilova (1976) and Reiss \& Säwedal (1981). Two of the species treated in Reiss \& Säwedal (1981) have older available names as indicated in Sæther \& Spies (2011) - P. confusus Palmén (1960) and P. intricatus Goetghebuer (1921) are junior synonyms respectively of $P$. dissimilis Johannsen (1905) and P. brevicalcar Kieffer (1909). Since the publication of Reiss \& Säwedal (1981) three additional western Palaearctic species are recognised: P. grimmii Schneider (1885) (a widespread parthenogenetic species redescribed by Langton et al. (1988) as larva, pupa and adult female), P. paralaccophilus Giłka \& Paasivirta (2008) (described as adult males from Finland) and P. praecellens Giłka (2009) (described as adult males from the United Arab Emirates on the Arabian Peninsula).

In this paper three new species are described based on the adult male and pupal exuviae: $P$. corsicanus sp. nov. from the outflow of Lake Calacuccia in Corsica, P. curvispinus sp. nov. from a coastal river in southern Lebanon and $P$. oconnori sp. nov. from temporary pools in southern France (Roque-Haute Domain). Consequently the number of species increases to 23 in the western Palaearctic. A total of five species are recorded from Lebanon and 13 species are reported from Continental France (Laville \& Serra-Tosio 1996; Delettre 2001; MoubayedBreil 2007; Sæther \& Spies 2011) but no species of the genus has previously been reported from Corsica.

For each species, remarks on the taxonomic position, ecology and known geographical distribution are given. The 
species $P$. bituberculatus appears to be absent from southern France and Lebanon where new sister species may occur.

\section{MATERIAL AND METHODS}

The adult, head, thorax, abdomen and anal segment were cleared of musculature in $90 \%$ lactic acid which took a minimum of 20-30 minutes - material can be left overnight at room temperature without any detrimental effect or damage. The specimens were checked under a binocular microscope after 20 minutes in lactic acid to determine how the clearing was progressing. When clearing was complete the specimens were washed in two changes of $70 \%$ Ethanol to ensure that all traces of lactic acid were removed. Compared to clearing with potassium hydroxide, or other clearing solutions, no deterioration of the typical "original" structure is reported by using lactic acid. More details on the above technique will be given in Moubayed-Breil \& Ashe (in prep.). All examined material (adults and pupal exuviae) was mounted in polyvinyl lactophenol. Before the final slide preparation was made the hypopygium was viewed laterally (to draw a side view of the anal point) and ventrally to examine or draw the median volsella before the hypopygium was turned into its permanent dorsal position and covered with a coverslip. If several adult specimens are available the eye on one side should be dissected from the head which ensures that the hairs on the inner margin of eye are more clearly visible. Terminology follows that of Sæther (1980) and Langton \& Pinder (2007) for the adult male (except for the types of median volsella setae or lamellae - see Ekrem 2001, 2002, Stur \& Ekrem 2006) and Sæther (1980) and Langton (1991) for the pupal exuviae.

\section{RESULTS}

Paratanytarsus corsicanus sp. nov.

(Figures 1, 4, 9-15, 19, 23-28, 32)

\section{Type material}

Holotype. FRANCE: Corsica, Golo River, outflow of Lake Calacuccia, altitude $790 \mathrm{~m}$, 5.vii.1997 (1 adult male), leg. J. Moubayed-Breil.

Paratypes: same locality, date and collector as holotype, 2 pupal exuviae (1 male, 1 female).

Holotype deposited in the collections of the National Museum of Ireland, Kildare Street, Dublin 2, Ireland. Paratypes in the collection of the senior author.

\section{Etymology}

The new species is named after the island of Corsica where the type material was collected.

\section{Diagnosis}

Male: $\mathrm{AR}=0.94$. Mesonotum with a very marked dark scutal mound mediodorsally. Anal tergite without tubercles medially, anal tergite bands abruptly terminated well before base of anal point; anal point dorsally drop-like in shape, broad basally, narrowed medially and spatulate at apex; atypicallly trianglelike in lateral view, crests include a few strong posteriorly directed spines basally and a bunch of point-like spinulae medially. Superior volsella subrectangular to suboval, bearing a finger-like apically rounded digitus of mostly equal width; median volsella triangle-like, uniformly narrowed distally and bearing numerous long bristle-like setae; inferior volsella bearing 2 well spaced setae ventrally.

Pupa: Frontal apotome with indistinct granulation laterally and on base of antennal sheaths. Cephalothorax with a marked granulose scutal hump or mound medially near the thoracic suture; thoracic horn absent; pearl row long, extending past the wing sheath apex and reaching the nose; pair of spine patch on tergite III composed of about 28-30 long spines inserted in a L-shaped line, D5 taeniate.

\section{Description}

Male adult and pupal exuviae of Paratanytarsus corsicanus sp. nov. are described based on material collected in the outflow of the Lake Calacuccia (altitude $790 \mathrm{~m}$ ), an artificial reservoir in central Corsica. On the basis of the finger-like digitus on the superior volsella (Reiss \& Säwedal 1981), P. corsicanus keys near P. penicillatus Goetghebuer, $P$. setosimanus (Goetghebuer), $P$. austriacus (Kieffer), P. baikalensis (Chernovskii), and P. tenuis (Meigen), while the pupa closely resembles $P$. bituberculatus.

Adult male $(\mathrm{n}=1)$ (Figures 1, 4, 9-13)

Large species. Total length $3.90 \mathrm{~mm}$. Wing length 2.30 $\mathrm{mm}$. Coloration in general light brown to dark brown. Head brown with both eyes and pedicel dark brown, antenna dark brown. Thorax dark yellow to medium brown with separated dark brown mesonotal stripes. Mesosternum, scutellum and postnotum brown. Wing yellowish with brownish shading between its base and the arculus. Halteres brownish. Legs dark yellow (all tarsi are missing). Femur of $\mathrm{P}_{1}$ brownish, darker on distal half; tibia yellowish medially, dark brown basally and apically. Femur of $\mathrm{P}_{2}$ and $\mathrm{P}_{3}$ dark brown at tip; tibia dark brown at both base and tip. Abdominal segments brownish to yellowish; anal segment brown with dark brown anal tergite bands; basal inner area of gonocoxite brown.

Head. $A R=0.94$. Antenna 13 segmented with distinct division between segments, $1.355 \mathrm{~mm}$ long, ultimate flagellomere 655 $\mu \mathrm{m}$ long. Eyes with bare ommatidia; hairs present on anterior inner margin of eyes (Figure 1). Clypeus with 16 setae. Palp segments 1 and 2 only present; length $115 \mu \mathrm{m}$ and $160 \mu \mathrm{m}$, respectively (palp segments 3 to 5 lost). Frontal tubercles strongly projecting. Coronal triangle widely open, bearing 4 small stout setae. Temporal setae 9-10 including 2 inner and 8-9 outer verticals. 
Thorax. Mesonotum with a very marked dark scutal mound mediodorsally. Thoracic setae: antepronotals absent; 10 acrostichals nearly reaching antepronotum; 7 dorsocentrals; 2-3 prealars; 8 scutellars. Haltere bearing 4 minute setae in a single row.

Wing. Membrane covered with setae becoming dense in distal quarter. All veins, except M, from base to crossvein RM with dense macrotrichia.

Legs. All tarsi lost. Measurements, in $\mu \mathrm{m}$, of femur and tibia are given below.

\begin{tabular}{lll}
\hline & fe & ti \\
\hline $\mathrm{P}_{1}$ & 1005 & 1990 \\
$\mathrm{P}_{2}$ & 1010 & 855 \\
$\mathrm{P}_{3}$ & 1255 & 1005 \\
\hline
\end{tabular}

Hypopygium (Figures 4, 9-13). Dorsal and ventral view (Figure 9). Tergite IX subtriangular, lacking tubercles medially, ending with wide-angled margins, bearing 4 setae medio-basally and about 14 setae distally. Anal tergite bands abruptly terminated well before base of anal point (Figure 9). Anal point $35 \mu \mathrm{m}$ long, maximum width 18-19 $\mu \mathrm{m}$ at base; in dorsal view (Figure 9), anal point drop-like in shape, broad basally, narrowed medially and spatulate at apex, bearing flattened to indistinct crests. In lateral view (Figure 4) the anal point is "atypically" triangular, bent downwards and pointed apically, crests include a few strong posteriorly directed spines basally and a bunch of point-like spinulae medially; 16 setae present on basal "apical" margin including 8 laterally (4 setae on each side), 3 dorsally and 5 ventrally. Sternapodeme with a characteristic horn-like base. Gonocoxite swollen at ventral inner base, which bears dense microtrichia; inner proximal margin with 3 setae, distal one is stouter and much longer than the preceding "two proximals". Superior volsella (Figures 10-11) subrectangular to suboval, $51 \mu \mathrm{m}$ long and $63 \mu \mathrm{m}$ wide; with 5 setae dorsally and 2 setae on inner lateral margin, bearing a finger-like, apically rounded, digitus of mostly equal width, broadened at base. Median volsella (Figure 12) 41-43 $\mu \mathrm{m}$ long, triangle-like, uniformly tapering distally, bearing numerous long bristle-like setae; longest setae 55-60 $\mu \mathrm{m}$ long. Inferior volsella (Figures 9, 13), $115 \mu \mathrm{m}$ long, $41 \mu \mathrm{m}$ maximum width; wider at base and uniformly narrowed distally; about 11-12 setae present laterodorsally, all stout and curved distally; 2 straight and stout setae of equal length (separated by a distance of 23-24 $\mu \mathrm{m}$ ) are located lateroventrally.

Pupal exuviae $(\mathrm{n}=2)($ Figures 14-15, 19, 23-28, 32)

Total length: $3.60 \mathrm{~mm}$ (female) - $3.95 \mathrm{~mm}$ (male); abdomen length $2.85 \mathrm{~mm}$ (female) $-3.15 \mathrm{~mm}$ (male). Colour brown, abdomen brownish, anal segment brown, genital sac brown with whitish tip.

Cephalothorax (Figures 14-15). Frontal tubercles (Figure 14) indistinct to domed and very broad, each with a long bristle 140-
$155 \mu \mathrm{m}$ long; frontal apotome with faint granulation apically, a few granules confined to the posterolateral area and warts present on base of antennal sheaths. Thoracic horn absent; three long, bristle-like, precorneal setae (on an inwards projecting eminence). Thoracic suture bearing dense granulation along anterior half and a domed scutal hump or "mound" (Figure 15), which bears minute faint granulation. Posterior thoracic mound large and smoothly rounded. Thorax with 2 long antepronotals; dorsocentrals Dc1-Dc4 in two paired groups widely separated from each other, Dc1-Dc2 and Dc3-Dc4 inserted almost on the same base; lengths of Dc1-Dc2 $(115 \mu \mathrm{m}$ and $140 \mu \mathrm{m})$ and Dc3-Dc4 (95 $\mu \mathrm{m}$ and $105 \mu \mathrm{m})$. Wing sheath (Figure 19) with long pearl row extended past wing sheath apex and reaching the nose.

Abdomen (Figures 23-28, 32). Armament pattern on tergites III-VII is slightly different in male (Figures 25a, 26a, 27a) and female (Figures 25b, 26b, 27b). Tergite I without shagreen; tergite II largely covered with shagreen; posterior half of tergite III with a pair of spine patches composed of long to medium sized spines, about 28-30 long spines are inserted in a curved line (L-shaped), D5 taeniate; tergites IV and V with a single transverse broadly oval to rounded antero-median patch with different sized spines, longest spines directed posterior (Figures 25-26); lateral longitudinal spine bands present on median part of tergites IV and V; tergite VI bearing an anterior subrectangular patch of short spines medially (Figure 27); tergite VII bearing only one anterior patch composed of minute spines. Lateral setae on abdominal segments I-V: I, with 1 seta; II-V with 4 setae. Lateral filaments "taeniae" on segments VIVIII: VI-VII (4); VIII (4-5). Anal comb (Figure 28) with 6-7 spines, longest spine $18 \mu \mathrm{m}$ long. Anal segment (Figure 32a, male and 32b, female) $195 \mu \mathrm{m}$ long (both male and female), maximum width $315 \mu \mathrm{m}$ (male), $250 \mu \mathrm{m}$ (female), bearing a long dorsal taenia; shagreen present only in the anterior part in both male and female, shagreen less intense in the female; apical margin distinctly straight. Genital sac $280 \mu \mathrm{m}$ long (male), $100 \mu \mathrm{m}$ long (female). Genital sac of male overreaching tip of anal segment by $110 \mu \mathrm{m}$; genital sac of female almost reaching tip of anal lobe; genital sac of male covered with evanescent granulation except in the apical part; genital sac of female bearing granulation apically. Fringe with 32-36 (in male), 33-35 (in female) taeniae.

\section{Female adult and larva: Unknown.}

\section{Remarks}

Within the known Paratanytarsus species from Europe and the Mediterranean Region (North Africa and the Near East), male imagines of $P$. corsicanus are easily separated from all other species by the following combination of characters: anal tergite lacking tubercles medially (present in P. bituberculatus, P. laccophilus, $P$. mediterraneus, $P$. penicillatus); anal tergite bands abruptly end medially (otherwise in many species); anal point with unusual shape in dorsal and lateral view (dorsally: 


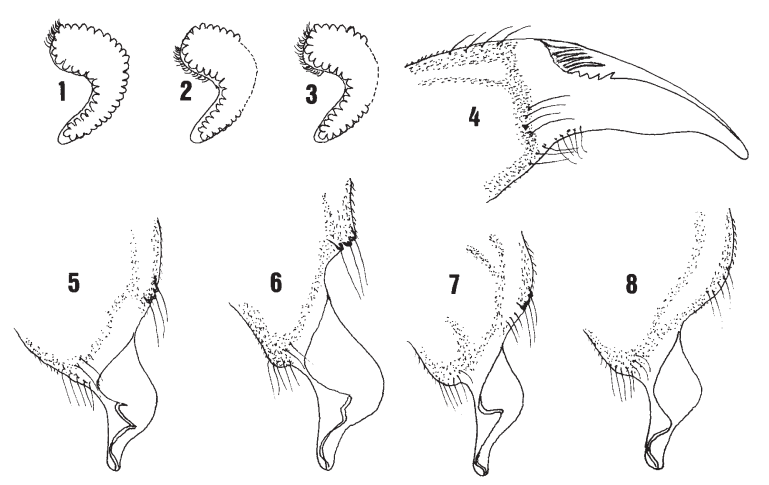

Figures I-8. Paratanytarsus spp. Hairs on inner margin of eyes: (1) $P$. corsicanus sp. nov.; (2) P. curvispinus sp. nov.; (3) P. oconnori sp. nov.; Anal point in lateral view of: (4) P. corsicanus sp. nov.; (5) P. curvispinus sp. nov.; (6) P. oconnori sp. nov.; (7) P. sp. A (near dissimilis Johannsen); (8) P. laccophilus (Edwards).

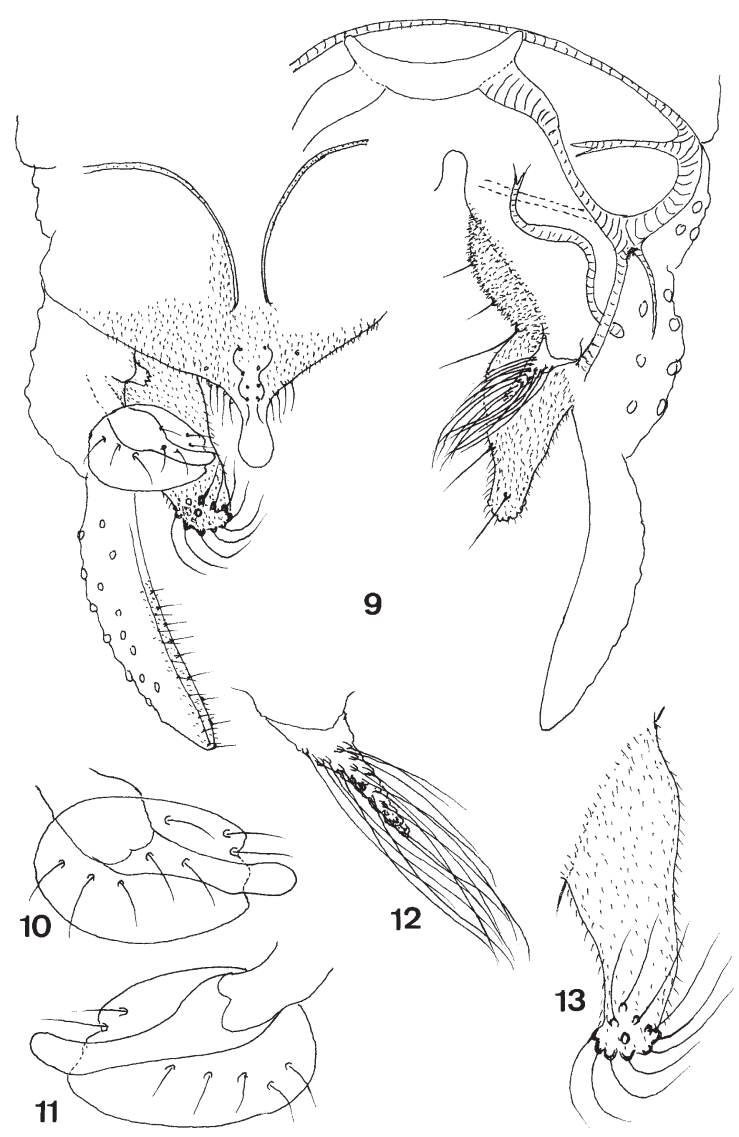

Figures 9-13. Paratanytarsus corsicanus sp. nov., hypopygium of adult male. Hypopygium, (9) in dorsal (left) and ventral (right) view. Superior volsella, (10) left, (11) right; (12) median volsella; (13) inferior volsella in dorsal view. narrowed medially and spatulate apically; laterally: triangular, pointed apically and bearing a flattened crest with spines and points); median volsella triangular and bearing long setae; inferior volsella straight, uniformly tapering distally and bearing 2 long straight and stout setae lateroventrally. However, $P$. corsicanus is closely related to some other species on the basis of the following characters: superior volsella with a fingerlike digitus as in P. penicillatus, P. setosimanus, P. baikalensis, $P$. tenuis and $P$. austriacus; median volsella bearing long simple
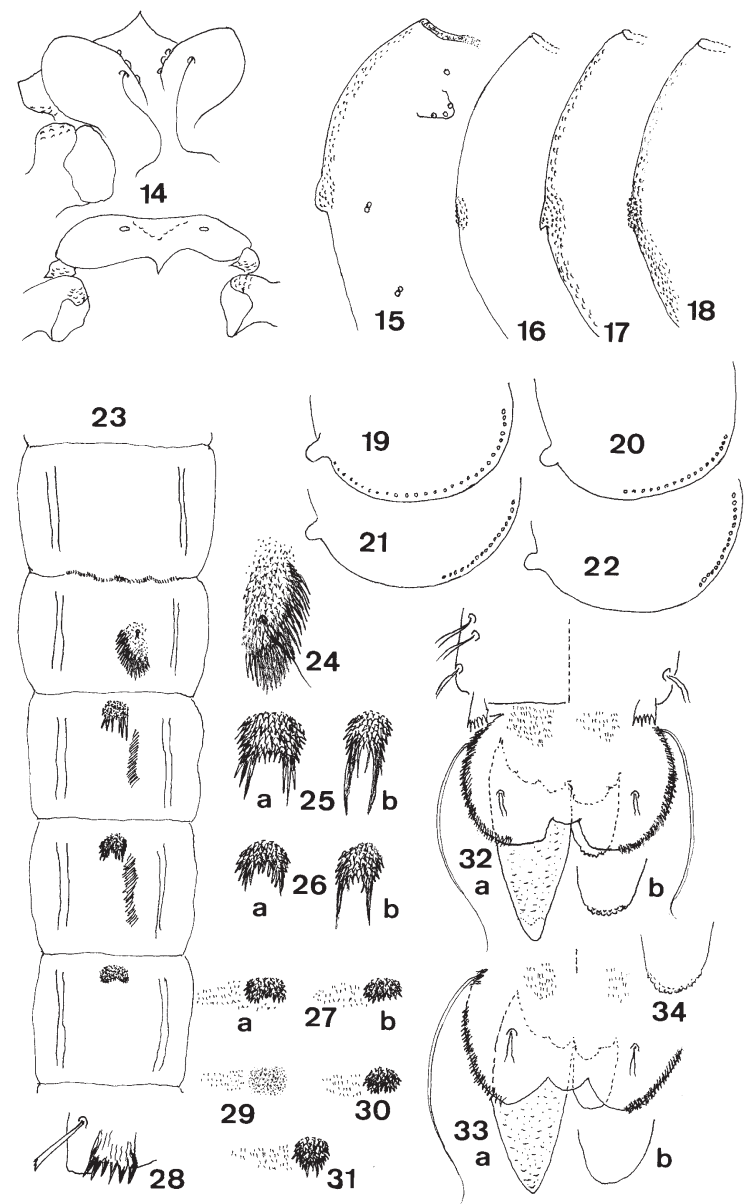

Figures 14-34. Paratanytarsus spp., pupal exuviae. Frontal apotome and antennal sheath: (14) P. corsicanus sp. nov. Cephalothorax including hump and granulations on thoracic suture of: (15) $P$. corsicanus sp. nov., (16) P. bituberculatus (Edwards), (17) $P$. curvispinus sp. nov., (18) P. oconnori sp. nov. Apical part of wing sheath of: (19) P. corsicanus sp. nov., (20) P. bituberculatus (Edwards), (21) P. curvispinus sp. nov., (22) P. oconnori sp. nov. Paratanytarsus corsicanus sp. nov., abdominal segments IIVI, (23). Shape pattern of median patch on tergites III-VI of $P$. corsicanus (24-27; male, a; female, b): (24) tergite III, (25) tergite IV, (26) tergite V, (27) tergite VI. Anal comb of P. corsicanus: (28). Median patch on tergite VI of: (29) P. bituberculatus (Edwards); (30) P. curvispinus sp. nov.; (31) P. oconnori sp. nov. Anal segment of male and female in dorsal and ventral view of: $P$. corsicanus sp. nov.: (32; male, a; female, b); P. bituberculatus (33; male, a; female, b). Genital sac of female of $P$. oconnori sp. nov. (34). 
setae distally as in P. penicillatus and P. setosimanus. Therefore, the absence of tubercles on the anal tergite, the unusual shape of the anal point in both dorsal and lateral view and the presence of a finger-like digitus on the superior volsella isolates $P$. corsicanus from species with similar male hypopygia.

The main features that separate the pupae of $P$. corsicanus from the bituberculatus-complex are: scutal hump on thoracic suture broad and bearing granulations; pearl row on the wing sheath extending up to the nose (shorter in P. bituberculatus); distribution pattern of armament on tergites (median patch on tergite VI with dark short spines as in figures 27, 30 and 31 in $P$. corsicanus; faint and only composed of points in $P$. bituberculatus); apical margin of anal lobe straight in $P$. corsicanus, while it is rounded in all the other examined species of the bituberculatus-complex, including P. bituberculatus from Europe (sensu Langton 1991, Figure 132d). Nevertheless,
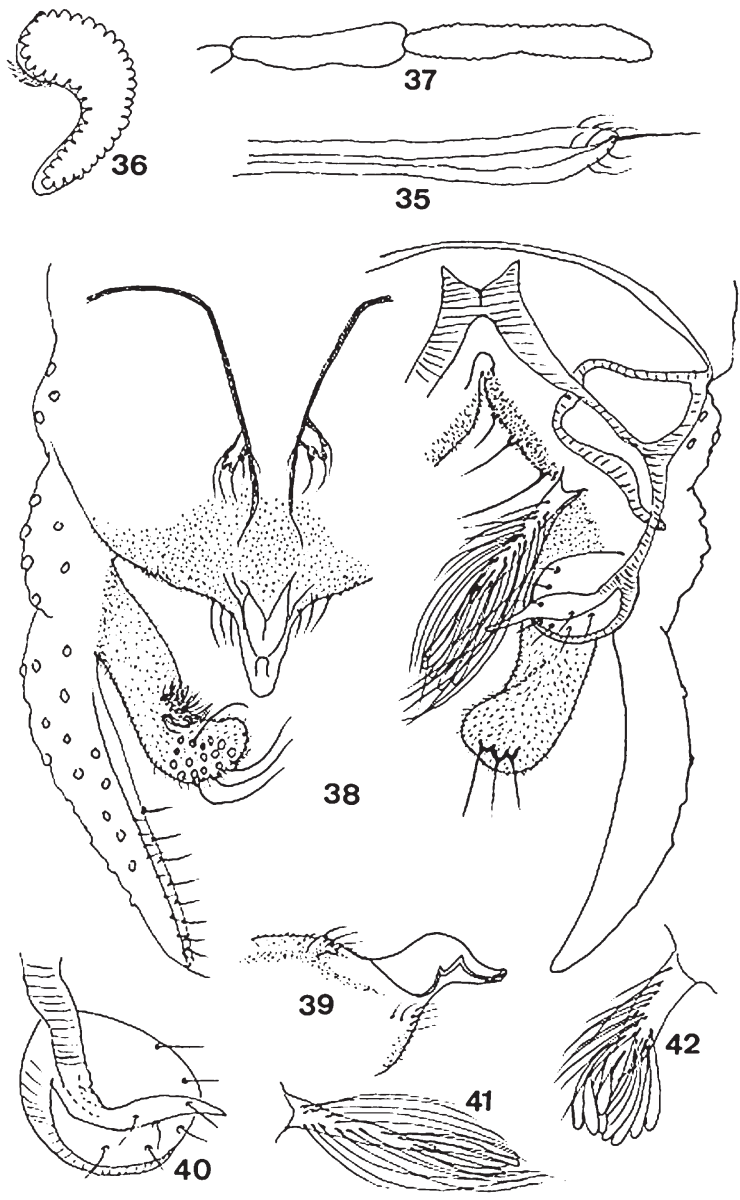

Figures 35-42. Paratanytarsus spp. Adult male of: P. curvispinus sp. nov. (35-41); P. bituberculatus (Edwards) (42). Paratanytarsus curvispinus sp. nov.: (35) last flagellomere of antenna, apical part; (36) hairs on inner margin of eyes; (37) $4^{\text {th }}$ and $5^{\text {th }}$ palpomeres; (38) hypopygium in dorsal (left) and ventral (right) view; (39) anal point in lateral view; (40) superior volsella, left; (41) median volsella, left. Paratanytarsus bituberculatus (Edwards) (42) median volsella (right).

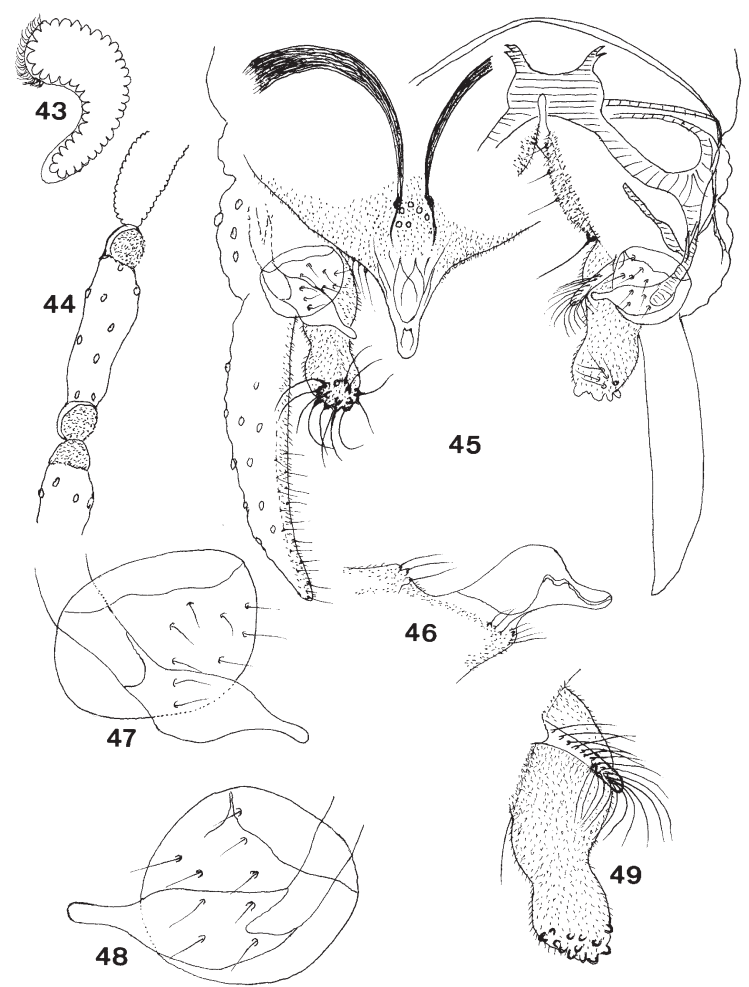

Figures 43-49. Paratanytarsus oconnori sp. nov., adult male: (43) hairs on inner margin of eyes; (44) $4^{\text {th }}$ palpomere; (45) hypopygium in dorsal (left), ventral (right) view; (46) anal point in lateral view; (47-48), superior volsella, 47 (left), 48 (right); (49) median and inferior volsella (left).

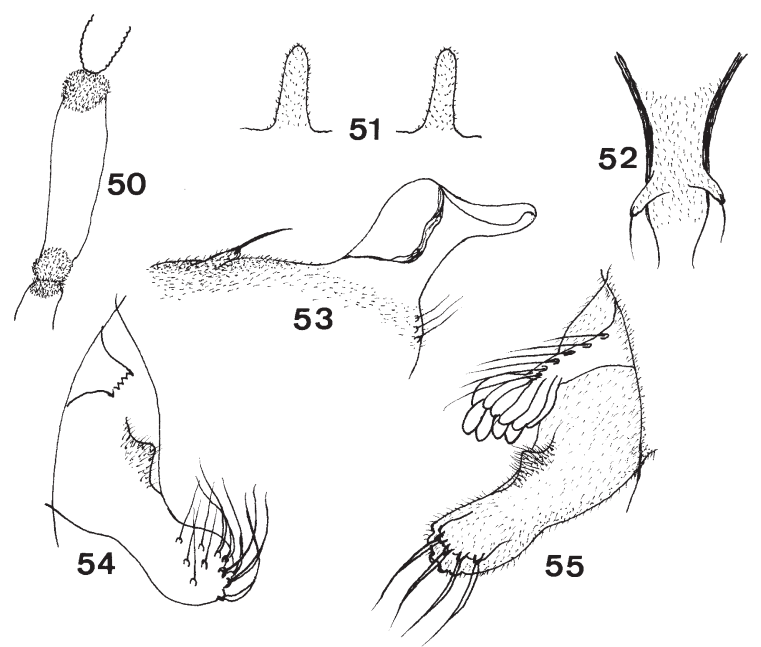

Figures 50-55. Paratanytarsus bituberculatus (Edwards), adult male (two specimens from Italy). (50) apical part of $3^{\text {rd }}$ palpomere, $4^{\text {th }}$ palpomere and basal part of $5^{\text {th }}$ palpomere; (51) frontal tubercles; (52) distal part of anal tergite bands; (53) anal point in lateral view; (54) inferior volsella (left) in dorsal view; (55) median and inferior volsella (right) in ventral view. 
morphological dimorphism in the shape of both adult male and pupal exuviae is often observed in some Paratanytarsus species such as $P$. dimorphis and P.dissimilis. In P. corsicanus the armament of tergites and shape of anal segments of pupal exuviae show a sexual dimorphism between male and female as in figures 25-27 for the patches of spines on tergites IV-VI and figures 32a-32b for the anal segment: apical spines on tergites IV and $\mathrm{V}$ are longer in the female (Figures 25-26); genital sac of male granulated except in the apical part (Figure 32a), genital sac of female only with apical granulation (Figure 32b).

\section{Ecology and geographical distribution}

Adult male and pupal exuviae of Paratanytarsus corsicanus are recorded only from the outflow of the mountain Corsican Lake Calacuccia (altitude $790 \mathrm{~m}$ ), where only a few emerged individuals were collected in July 1997. Species emergence presumably occurs mainly in the late spring. Larvae of this species seem to be stenotypically restricted to the profundal zone of Lake Calacuccia.

Several aquatic insect groups of mountain streams in Corsica (Trichoptera, Plecoptera, Diptera, etc.) display high levels of endemism (Giudicelli 1975), e.g. in the Trichoptera there are 30 endemic species ( $49 \%$ of the known species from the island). Despite extensive investigations, P. corsicanus has not been found in southern France, Italy, Spain or other western Mediterranean islands. However, the new species represents an additional lentic element to the Tyrrhenian subregion which includes, according to Furon (1950, 1972), the Italian Peninsula, Corsica, Sardinia and Sicily. It is possible that $P$. corsicanus may eventually be found elsewhere within the western Mediterranean subregion including low to middle mountain lakes located to the south in North Africa (Algeria, Morocco) and westwards in the Iberian Peninsula and the Eastern Pyrenees. The lotic chironomid fauna of Corsica has been listed (Laville \& Langton 2002). However there is very little data available on the lentic species there and the discovery of a new species from a lake may merely reflect the lack of extensive investigation of standing water habitats throughout the island.

Other associated chironomids from the western Mediterranean include: Chaetocladius (Chaetocladius) algericus Moubayed, Cricotopus (Cricotopus) beckeri Hirvenoja, C.(C.) levantinus occidentalis Moubayed-Breil \& Ashe, Krenosmittia hispanica Wülker, Parakiefferiella wuelkeri Moubayed, Stempellinella reissi Casas \& VilchezQuero, Pseudorthocladius (Pseudorthocladius) berthelemyi Moubayed, Orthocladius (Mesorthocladius) vaillanti Langton \& Cranston, Parametriocnemus valescurensis Moubayed \& Langton, Rheotanytarsus dactylophoreus Moubayed-Breil, Langton \& Ashe and Stygocladius multisetosus MoubayedBreil, Ashe \& Langton.

\section{Paratanytarsus curvispinus sp. nov.}

(Figures 2, 5, 17, 21 30, 35-41)

\section{Type material}

Holotype. LEBANON: southern Lebanon, Awaly River, altitude 250-350 m, hyporhithral to epipotamal zones, 7.xi.1997 (1 pharate male), leg. J. Moubayed-Breil.

Holotype deposited in the collections of the National Museum of Ireland, Kildare Street, Dublin 2, Ireland.

\section{Etymology}

This species is named after the markedly curved spine-like scutal tubercle or hump (from the Latin: curvus meaning curved, spinus meaning spine) on the thoracic suture of the pupal exuviae. A scutal tubercle is also present on the scutum of the adult. The name curvispinus is treated as a noun in apposition.

\section{Diagnosis}

Paratanytarsus curvispinus sp. nov. is closely related to $P$. bituberculatus on the basis of both male imagines and pupal exuviae features. Distinguishing characters for the male are: $\mathrm{AR}=1.2$; hairs present on the anteromedian inner margin of the eyes; Palp 5-segmented, without sensilla clavata; $4^{\text {th }}$ palpomere with cordiform apex and lacking circular patch of microtrichia; thorax with a markedly distinct scutal tubercle mediodorsally; sternapodeme with a characteristic V-like base, bearing two pointed anterior horns; anal point wider at base and progressively narrowed distally, in lateral view crests include 2 sharp points medially, proximal one the smaller; posterior margin of superior volsella rounded; digitus swollen at base, not uniformly tapering apically; median volsella not flattened distally, bearing about five spatulate setae; inferior volsella with distal $1 / 4$ swollen and bearing a tuft of short dark setae on distal $1 / 4$ inner margin, ventral setiferous lobe with 3 straight stout setae bent downwards. Pupal exuviae characters key to those of $P$. bituberculatus except: pattern and granulation of thoracic suture and scutal hump (hump pointed and granulations extended anteriad and posteriad); shape of median patch on tergite VI only composed of short dark spines.

\section{Description}

Adult male ( $\mathrm{n}=1$ ) (Figures 35-41)

Large species. Total length $4.30 \mathrm{~mm}$. Wing length $1.55 \mathrm{~mm}$. Head light brown with dark brown eyes, dark brown pedicel and brown flagellum. Thorax medium brown to brown with dark brown mesonotal stripes; mesosternum, scutellum and prosternum brown. Wing brownish. Legs light brown. Abdomen and anal segment brownish, except base of both sternapodeme and gonocoxite, which are dark brown.

Head. $A R=1.2$. Antenna with 13 flagellomeres, $1.32 \mathrm{~mm}$ long, ultimate flagellomere $720 \mu \mathrm{m}$ long, bearing one apical stout seta and 8-9 sensilla chaetica (Figure 35). Eyes with bare ommatidia; hairs present on anteromedian inner margin of eyes (Figure 36). 
Clypeus with 25 setae in 5 rows $(9,5,5,3,3)$. Palp 5 -segmented, without sensilla clavata; $4^{\text {th }}$ palpomere with cordiform apex and lacking circular patch of microtrichia (Figure 37); length (in $\mu \mathrm{m}$ ) of segments: 57, 51, 147, 103, 151. Frontal tubercles well developed. Coronal triangle moderately marked bearing 4 small stout coronals. Temporal setae 12 including 3 inner and 9 outer verticals.

Thorax. Scutum bearing a distinct scutal tubercle mediodorsally. Thoracic setae: antepronotals absent; 21 biserial acrostichals; 10 uniserial dorsocentrals; 2 prealars; 7 scutellars.

Wing. Membrane covered with setae becoming progressively dense in distal 1/4; all veins except $\mathrm{M}$, with dense macrotrichia. Legs. Pulvilli well developed, a little longer than claw. Measurements (in $\mu \mathrm{m}$ ) of legs are given below.

\begin{tabular}{cccccccc}
\hline & $\mathrm{fe}$ & $\mathrm{ti}$ & $\mathrm{ta}_{1}$ & $\mathrm{ta}_{2}$ & $\mathrm{ta}_{3}$ & $\mathrm{ta}_{4}$ & $\mathrm{ta}_{5}$ \\
\hline $\mathrm{P}_{1}$ & 624 & 675 & 948 & 507 & 442 & 390 & 195 \\
$\mathrm{P}_{2}$ & 911 & 779 & 546 & 282 & 338 & 208 & 143 \\
$\mathrm{P}_{3}$ & 975 & 1065 & 611 & 416 & 390 & 247 & 156 \\
\hline
\end{tabular}

Hypopygium (Figures 38-41). Tergite IX subrectangular to subcircular, ending with a nearly straight apical margin, bearing 8 setae situated mediodorsally on two strongly projecting tubercles, 12 setae present distally. Anal tergite bands regularly thin from base to nearly posterior limit of anal tergite, abruptly bent outwards basally, straight and converged medially and weakly terminated in an outwards arc which ends abruptly close to the base of the anal point. Anal point (Figure 38) 33 $\mu \mathrm{m}$ long, maximum width $26 \mu \mathrm{m}$ at base, wider at base and progressively narrowed distally, ending with a rounded apex; in lateral view (Figure 39) crests include 2 sharp points medially, proximal one the smaller; 12 setae present basally including 6 laterally ( 3 on each side) and 6 ventrally. Sternapodeme with a characteristic wide V-like base, bearing two pointed anterior horns. Gonocoxite moderately swollen at ventral inner base, which bears dense microtrichia; inner basal margin bearing 3 stout setae, distal one is stouter and longer than the preceding. Superior volsella (Figures 38, 40) subcircular to suboval bearing 8 setae including 4-5 on inner margin; digitus 41 $\mu \mathrm{m}$ long, swollen at base, not uniformly tapering distally and bearing a pointed apex. Median volsella (Figures 38, 41) $60 \mu \mathrm{m}$ long, not flattened distally, covered with long bristle-like setae and about 5 spatulate setae apically. Inferior volsella (Figure 38) $135 \mu \mathrm{m}$ long, nearly straight with distal $1 / 4$ swollen, bent and curved upwards; dorsally, a tuft of short dark setae on distal $1 / 4$ inner margin and bent inwards, about 18 curved stout setae are located apically; ventral setiferous lobe with 3 stout setae about 53-55 $\mu \mathrm{m}$ long, bent downwards. Gonostylus bearing two longitudinal rows of fine setae on inner margin (about 9 setae on each row).

Pupal exuviae $(\mathrm{n}=1)$ (Figures 17, 21, 30)

Thoracic horn absent. The pupal exuviae of $P$. curvispinus sp. nov. keys to $P$. bituberculatus as do those of $P$. corsicanus. Main distinguishing characters are: thoracic suture (Figure 17) densely covered with granulations on both anterior and posterior half, scutal hump granulate, bent downwards and pointed apically; pearl row on the wing sheath short, not reaching the nose, extending to end of the apical curvature of the wing sheath; postero-median patch of spines on tergite III bearing about 17 long spines on each side, longest spines are inserted in a short rounded row, D5 bristle-like; median patch on tergite VI (Figure 30) subcircular to suboval, bearing dark short spines. Anal lobe with rounded apical margin. Genital sac of male lacking granulations apically.

\section{Female adult and larva: Unknown.}

\section{Remarks}

P. curvispinus sp. nov. is closely related to $P$. bituberculatus on the basis of both male imagines and pupal exuviae. The following combination of distinguishing features for the male are: posterior margin of superior volsella rounded in $P$. curvispinus (Figure 40), straight in P. bituberculatus; digitus swollen at base, not uniformly tapering distally; median volsella short and bearing more than 10 spatulate setae apically in P. bituberculatus, while in P. curvispinus it has only about 5; ventral setiferous lobe of inferior volsella with 3 stout setae instead of 4 in $P$. bituberculatus. Pupal exuviae of $P$. curvispinus sp. nov. can be easily distinguished from those of the bituberculatus-complex on the basis of the following characters: pattern and granulation of thoracic suture (Figure 17, granulations extended anterior and posterior, hump pointed); shape of the median patch on tergite VI (Figure 30).

\section{Ecology and geographical distribution}

Paratanytarsus curvispinus is only known from southern Lebanon where it inhabits both the hyporhithral and the epipotamal zones of the Awaly River Basin at an altitude of $250-350 \mathrm{~m}$. This species represents an additional faunal element for the Levantine subregion.

\section{Paratanytarsus oconnori sp. nov.}

(Figures 3, 6, 18, 22, 31, 34, 43-49)

\section{Type material}

Holotype. FRANCE: Hérault, Roque-Haute Domain, temporary deep pools, altitude 25-30 m, 21.v.1995 (1 pharate male), leg. J. Moubayed-Breil.

Paratypes: same locality as holotype, 23.iii.1997 (1 male adult and 1 female pupal exuviae), leg. J. Moubayed-Breil (in the collection of the senior author); same locality as holotype, basaltic lake at the cliff, altitude $15 \mathrm{~m}$, 3.viii. 2001 (1 pharate male), leg. J. Moubayed-Breil (in the collection of P. H. Langton). Holotype deposited in the collections of the National Museum of Ireland, Kildare Street, Dublin 2, Ireland. 


\section{Etymology}

This species is named after our colleague Dr James P. O'Connor who recently retired from the National Museum of Ireland. He continues his research as Emeritus Entomologist in the museum and has to date to his credit 452 publications.

\section{Diagnosis}

In general, male adult characters of $P$. oconnori sp. nov. are closely similar to those of both $P$. natvigi Goetghebuer and P. dissimilis Johannsen. Distinguishing features for the male are: hairs present on anterior half of inner margin of the eyes; palp without sensilla clavata; $3^{\text {rd }}$ and $4^{\text {th }}$ palpomeres bearing a patch of minute macrotrichia (apically on segment 3, basally and apically on segment 4); thorax with minute scutal tubercle mediodorsally; sternapodeme with a swollen rectangular base, bearing two characteristic nozzle-like horns; anal point wider at base and progressively narrowed distally with rounded apex, in lateral view crests include 2 smooth peaks medially, proximal peak a little higher than the distal one; superior volsella subcircular to subrectangular with rounded posterior margin; digitus wider at base, abruptly tapering medially and ending with a rounded apex; median volsella short, slightly flattened distally, bent downwards, bearing only simple setae, posterior margin with 7-8 setae distinctly bent downwards; inferior volsella with basal half swollen, distal half less swollen, 5 straight and slender setae are present ventrally. Pupal exuviae characters key to those of $P$. bituberculatus but can be easily separated by the following features: thoracic suture with dense granulations only on posterior half, anterior half faintly granulose; scutal hump densely granulose and weakly domed; pearl row on the wing sheath short, not reaching the nose, median patch on tergite VI circular, bearing dark short to medium sized spines, 2 longer spines projecting posteriorly; genital sac of male covered with granulations as in P. bituberculatus and P. corsicanus, genital sac of female bearing granulations apically as in $P$. corsicanus.

\section{Description}

Adult male ( $\mathrm{n}=3$ ) (Figures 43-49)

Large species. Total length $4.60-4.65 \mathrm{~mm}$. Wing length (paratype) $2.30 \mathrm{~mm}$. Dark brown to blackish in general. Head brown to dark brown with both eyes and pedicel blackish. Antenna (partial in holotype and paratype) with dark brown proximal segments. Palpomeres with dark brown segments. Thorax dark brown to blackish with black mesonotal stripes; mesosternum, scutellum and prosternum dark brown. Wing with both membrane and veins medium brown to dark brown. Legs dark brown to blackish. Abdomen and anal segment dark brown to blackish including both sternapodeme gonocoxite and gonostylus; only anal point and IX tergite are brown.

Head. AR not measurable (distal $1 / 4$ of last flagellomere missing). Eyes with bare ommatidia; hairs present on anterior half of inner margin of eyes (Figure 43). Clypeus with 23-24 setae located in 5 rows: $3,3,5-6,6,6$. Palp with 5 segments; $3^{\text {rd }}$ and $4^{\text {th }}$ palpomeres (Figure 44 ) bearing patch of minute microtrichia: apically on segment 3 , basally and apically on segment 4; last segment bearing minute sensilla chaetica apically, length (in $\mu \mathrm{m}$ ) of palpomeres: 65, 88, 195, 205, 265. Frontal tubercles domed. Coronal triangle well marked bearing 4 small stout coronals. Temporal setae 11 including 2 inner and 9 outer verticals.

Thorax. Scutum bearing a minute scutal tubercle mediodorsally. Thoracic setae: antepronotals absent; 18 biserial acrostichals; 29-31 dorsocentrals often biserial; 0-1 prealars; 2 humerals; 8 uniserial scutellars.

Wing. All veins bearing setae except M; membrane covered with macrotrichia progressively becoming dense in distal 1/4.

Legs. Pulvilli moderately developed, a little longer than claw; tibial comb of $\mathrm{P}_{3}$ semicircular, maximum height $117 \mu \mathrm{m}$, maximum width $235 \mu \mathrm{m}$, composed of 19-20 short spines with rounded apex, of equal size (about 37-39 $\mu \mathrm{m})$. Legs $\left(\mathrm{P}_{1}\right.$ and $\mathrm{P}_{2}$ incomplete), measurements, in $\mu \mathrm{m}$, as follows.

\begin{tabular}{cccccccc}
\hline & $\mathrm{fe}$ & $\mathrm{ti}$ & $\mathrm{ta}_{1}$ & $\mathrm{ta}_{2}$ & $\mathrm{ta}_{3}$ & $\mathrm{ta}_{4}$ & $\mathrm{ta}_{5}$ \\
\hline $\mathrm{P}_{1}$ & 1260 & 1055 & & & & & \\
$\mathrm{P}_{2}$ & 1315 & 1145 & 675 & & & & \\
$\mathrm{P}_{3}$ & 1560 & 1150 & 665 & 405 & 325 & 208 & 156 \\
\hline
\end{tabular}

Hypopygium (Figures 45-49). Tergite IX subtriangular, ending with a quite wide V-like apical margin, bearing 8 setae situated mediodorsally on 2 weakly projecting tubercles, 10 setae present distally. Anal tergite with weakly developed tubercles medially, tergite bands very thick at base, becoming progressively thin from base to median part of anal tergite, parallel side medially and terminated with an outwards arc close to the base of the anal point crests. Anal point in dorsal view (Figure 45) $46 \mu \mathrm{m}$ long, maximum width $35 \mu \mathrm{m}$ at base, wider at base and narrowed distally with rounded apex; in lateral view (Figure 46) crests include 2 smooth peaks medially, proximal peak a little higher than the distal; 11-12 setae present basally including 6 laterally ( 3 on each side) and 4-5 ventrally. Sternapodeme with a swollen rectangular base, bearing two characteristic nozzle-like horns. Gonocoxite moderately swollen at ventral inner base, which bears dense microtrichia; inner basal margin bearing 4 stout setae, distal one is much stouter and longer than the preceding. Superior volsella (Figures 47-48) subcircular to subrectangular with rounded posterior margin; bearing 9 setae including 4 lateroventrally and 5 medially; digitus $48 \mu \mathrm{m}$ long, maximum width $16 \mu \mathrm{m}$, wider at base, abruptly tapering medially and ending with a rounded apex. Median volsella (Figures 45, 49) 55-57 $\mu \mathrm{m}$ long, short and slightly flattened distally, bearing short to medium sized simple setae; posterior margin with 7-8 comb-like setae which are bent downwards. Inferior volsella (Figure 45, 49) $113 \mu \mathrm{m}$ long, maximum width $41 \mu \mathrm{m}$, nearly divided longitudinally into two swollen lobes, basal half wider than distal half; in dorsal view, 12-13 curved stout setae near the apex; in ventral view, presence of 5 slender setae which are 
bent inwards. Gonostylus bearing two longitudinal rows of fine setae on inner margin (about 8-9 setae on each row).

Pupal exuviae $(\mathrm{n}=3)$ (Figures 18, 22, 31, 34)

In general pupal exuviae of $P$. oconnori sp. nov. key close to those of other species in the bituberculatus-complex and to $P$. corsicanus. Main distinguishing characters are: thoracic suture (Figure 18) covered with dense granulations on posterior half, anterior half with faint granulations; scutal hump densely granulose and weakly domed; pearl row on the wing sheath short (Figure 22), not reaching the nose, extending to end of apical curvature of sheath; postero-median patch of spines on tergite III bearing about 15 long spines on each side, longest spines are inserted in a short rounded row, D5 taeniate; median patch on tergite VI (Figure 31) circular, bearing dark short to medium sized spines, 2 longer spines project posteriad; genital sac of male covered with granulations as in P. bituberculatus and P.corsicanus, genital sac of female (Figure 34) bearing granulations apically as in $P$. corsicanus.

\section{Female adult and larva: Unknown.}

\section{Remarks}

Very similar to both $P$. natvigi Goetghebuer and $P$. dissimilis, the male adult of $P$. oconnori sp. nov. is mainly distinguished from other related species on the basis of the legs and hypopygium: tibial comb of $\mathrm{P}_{3}$ bearing more than 30 smooth spines in $P$. dissimilis, less than 20 smooth spines in P. oconnori; anal point in dorsal view uniformly tapering apically in $P$. oconnori (Figure 45), parallel sided to drop-like in $P$. dissimilis (Giłka 2011, Figures 123-124; Palmén 1960, Figure 2); in lateral view presence of 2 smooth peaks in P. oconnori (Figures. 6 and 46), presence of only 1 peak in $P$. sp. A (near dissimilis) (Figure 7); superior volsella subcircular to subrectangular, bearing a rounded posterior margin; median volsella short, weakly flattened distally, bearing a different combination of simple setae on apical part; inferior volsella wider basally, constricted medially and moderately swollen distally, stout and curved setae present on dorsal apex, 5 slender setae present ventrally, which are bent inwards. Pupal exuviae of $P$. oconnori resembles those of P. bituberculatus; it is separated from other related species by the following characters: hump on thoracic suture bearing dense granulation (Figure 18); granulations on thoracic suture extended anteriorly and posteriorly; median patch of spines on tergite VI dark and bearing 2 longer apical spines (Figure 31 ); only genital sac of female bearing granulations apically (Figure 34).

\section{Ecology and geographical distribution}

The species $P$. oconnori is only known from the type locality at Roque-Haute Domain, in southern France, where it was found in pools, lentic springs, a basaltic lake and slow flowing streams. Aquatic plants which occur in these habitats include Potamogeton, Scirpus, Ranunculus, Juncus, Alisma, Isoetes and Marsilea.

Paratanytarsus bituberculatus (Edwards 1929)

(Figures 16, 20, 29, 33a, 33b, 42, 50-55)

Synonym: Paratanytarsus atrolineatus (Goetghebuer 1937)

Imago: Reiss 1968; Langton \& Pinder 2007; Giłka (2011).

Pupa: Thienemann 1951; Reiss \& Säwedal 1981 (? pupa); Langton 1991; Langton \& Visser (2003).

\section{Female adult and larva: Undescribed.}

\section{Material examined}

FRANCE: Aude, Aude River, epipotamal zone, altitude 50-60 m, 23.iv.1995 (1 male pupal exuviae), leg. J. Moubayed-Breil; Normandy, Valmont River, 5.xi.1997 (1 male pupal exuviae), leg. J. Moubayed-Breil; SPAIN: Andalucía, Sierra Almijara, Barranco de Luna, 21.iii.1999 (1 pharate male), leg. J.J. Casas (in collection of P.H. Langton); IRELAND: Co. Meath, Navan, Randalstown, N855704, leg. D.A. Murray (specimen in National Museum of Ireland), 14.v.1996 (1 male adult); ITALY: Milan, Botanic Garden, 12.viii.1980 (2 pharate males and 1 male pupal exuviae), leg. B. Rossaro.

\section{Diagnostic characters}

Only the main distinguishing characters of both adult males and pupal exuviae are given.

Male adult. AR $=1.25-1.35$. Palpomere 3 with only one apical patch of microtrichia, palpomere 4 with two patches of microtrichia, basally and distally (Figure 50); frontal tubercles 22-25 $\mu \mathrm{m}$ long (Figure 51), well projecting. Anal tergite (Figure 52) with 2 marked tubercles bearing 2 setae apically (Italian specimen has only one seta on each tubercle); anal point in lateral view with one median well projecting peak bearing a domed proximal margin (Figure 53); superior volsella semicircular with apical margin nearly straight and bearing a narrowed long digitus; median volsella (Figures 42, 55) short with numerous spatulate setae distally; inferior volsella (Figures 54-55) strongly widened and swollen at base, constricted distally, bearing a triangular lobe medially, setiferous ventral lobe well defined and bearing 4 stout setae (Figure 55).

Pupal exuviae. General shape pattern of abdomen as in Figure 23. Granulations on thoracic suture absent (Figure 16), only scutal hump is faintly granulose; thoracic horn absent; pearl row on wing sheaths short (Figure 20). Pair of spine patches on posterior half of tergite III composed of about 13-15 spines inserted nearly in a L-shaped line, D5 bristle-like or taeniate (taeniate in Italian specimens); point patch on tergite VI (Figure 29) subcircular, not darkened, composed of faint points. Anal lobe (Figures 33a, 33b) with rounded apical margin, genital sac of male with dense granulations including apical part, genital sac of female without granulations. 


\section{Remarks and geographical distribution}

Reiss \& Säwedal (1981: 94) in a key indicate that the pupal exuviae of $P$. bituberculatus has a thoracic horn but in Langtom (1991: 327, Plate 132b) the thoracic horn is regarded as absent in this species and the latter viewpoint is accepted here.

The pupal exuviae of $P$. bituberculatus resemble closely those of $P$. corsicanus, $P$. curvispinus and $P$. oconnori. Main separating characters for $P$. bituberculatus are: thoracic suture (Figure 16) lacking granulations on both anterior and posterior half; thoracic horn absent; scutal hump faintly granulose and not domed (Figure 16); pearl row on the wing sheath (Figure 20), not reaching the nose; median patch on tergite VI (Figure 29) circular, bearing faint to weakly darkened points; genital sac of male covered with granulations (Figure 33a), genital sac of female (Figure 33b) lacking granulations apically. However, some variation in the male imagines and the pupal exuviae $P$. bituberculatus from Italy include: tubercles on anal tergite of male bearing only a single seta; thoracic suture with faint granulations on anterior half; D5 on tergite III taeniate.

\section{DISCUSSION}

Associated material composed of pupal exuviae and pharate males belonging to the bituberculatus-complex (with pupae that key to P. bituberculatus in Langton 1991 and Langton \& Visser 2003) described here demonstrates that there is a risk of misidentifying pupal exuviae similar to P. bituberculatus as $P$. bituberculatus. Consequently, we believe that populations of $P$. bituberculatus from Europe and neighboring regions include about five new species, which key to P. bituberculatus as pupal exuviae. It appears that true $P$. bituberculatus is more a northern element than a widespread species throughout the Palaearctic Region. Therefore, the presence or absence of P. bituberculatus from some subregions in Europe and the Mediterranean Region needs to be reviewed and confirmed on the basis of pharate males or adult males, in particular from southern Europe (including Portugal, Spain, France, Italy, Greece) and the Near East. Details on both the taxonomy and biogeography of the bituberculatus-complex are given in a separate paper in preparation.

In the bituberculatus-complex, based on the morphology of both male adult and pupal exuviae, there appear to be several species groups, one centering on P. bituberculatus with several close but distinct sister species and another which includes only P. corsicanus sp. nov. Further investigations throughout Europe, North Africa and the Near East are necessary to determine if imaginal and pupal features support each other and enable the creation of species groups within the entire genus.

Paratanytarsus. bituberculatus has been previously accepted as having a widespread distribution throughout the Palaearctic Region including southern Europe, the Near East and North Africa. Our investigations show that several species morphologically similar to P. bituberculatus, occur in the
Mediterranean Basin region. Two of these, P. curvispinus and P. oconnori, which we consider members of the bituberculatuscomplex, are described in this paper. In the light of these new discoveries the geographical distribution of $P$. bituberculatus needs to be reviewed by focusing especially on examining pharate males and adult males. Taxonomic information given in this paper provides additional characters for keying any further related species which fall into the bituberculatus-complex. Additional future work needs to be done on both the taxonomic composition and geographical distribution of all members of the bituberculatus-complex.

The biological quality of both water and sediment in wetland areas and lower reaches of coastal rivers is seriously damaged by the impact of organic and chemical pollution in many countries around the Mediterranean Basin. Furthermore, despite extensive investigations during the last three decades in southern France and Lebanon, only a few pharate males and pupal exuviae belonging to the bituberculatus-complex have been obtained.

Coastal aquatic ecosystems including coastal rivers in southern and western France (Mediterranean and Atlantic coastal areas) have been heavily affected by toxic chemical pollutants such as HAP's and PCB's. The latter products combined with the anti-mosquito solution BTI and the past use of pesticides such as Fipronil and Lindane (which remain in the sediments and take a long time to breakdown) can lower the chironomid diversity in coastal habitats by 30 to $50 \%$ (Moubayed-Breil, personal observation).

\section{Key to related known adult males and pupal exuviae Adult male}

As in most Tanytarsini, variation in the superior and median volsella, and the shape of the anal point, provide good distinguishing characters which are often used as main key features for the identification of species. Details of the median volsella in particular, for accurate observation, are more clearly visible when the hypopygium is temporally mounted ventral side uppermost or if the median volsella is dissected from the rest of the hypopygium.

In the following keys, for the identification of adult males and pupal exuviae, only those species, known from Europe and the Near East, belonging to the bituberculatus-complex (P. bituberculatus, P. curvispinus and P. oconnori) and $P$. corsicanus are fully keyed.

\section{Adult males}

1. Anal tergite without tubercles medially; Anal tergite bands terminating abruptly, well before base of anal point (Figure 9); Anal point (in dorsal view) broad basally, constricted medially, expanded apically to drop-like apex (Figure 9), (in lateral view) triangular (Figure 4); Superior volsella suboval (Figures 10-11); Digitus long and fingerlike, equally broad, with rounded apex (Figures 10-11); Median volsella short, triangular bearing only long bristle- 
like setae (Figure 12); Inferior volsella wider at base, straight and uniformly tapering (Figures 9, 13), bearing 2 widely spaced setae ventrally (Figure 9), setiferous ventral lobe absent P. corsicanus sp. nov.

- Anal tergite with or without tubercles medially; Anal tergite bands terminating near base of anal point (Figures 38, 45, 52); Anal point (in dorsal view) evenly tapered to rounded apex (Figures 38, 45), (in lateral view) not triangular (Figures 5-6, 39, 46, 53); Superior volsella subcircular, subtriangular or subrectangular; Combination of digitus, median volsella and inferior volsella not as described above 2

2. Anal tergite without tubercles medially . other Paratanytarsus species [Not keyed] Anal tergite with tubercles medially bituberculatuscomplex .... 3

3. Median volsella with simple setae (Figures 45, 49); Digitus very broad basally, abruptly constricted medially, and evenly continuing to rounded apex (Figures 47-48); Anal tergite with weakly developed tubercles medially (Figure 45) P. oconnori sp. nov.

- Median volsella with spatulate lamellae (Figures 41-42); Digitus not as above, with pointed apex (Figure 40); Anal tergite with very distinct tubercles medially (Figures 38, 52)

4. Inferior volsella straight, with a triangular lobe projecting beyond the inner margin (Figure 54, Reiss \& Säwedal 1981, Figure 9), ventrally bearing 4 setae on a distinct subapical lobe (Figure 55); Tubercles on anal tergite smaller, usually with 2 setae (rarely 1 seta) (Figure 52); Median volsella, short and broad, not tapering, with simple setae and 10 to 11 spatulate setae distally, simple setae reaching to about one-half length of inferior volsella (Figures 42, 55); Palpomeres 3 (apically) and 4 (basally and apically) with patches of microtrichia (Figure 50)

P. bituberculatus (Edwards 1929)

- Inferior volsella bent inwards apically, with a distinctive tuft of dark setae on inner margin (Figure 38), ventrally bearing 3 setae but without a distinctive subapical lobe (Figure 38); Tubercles on anal tergite larger, with 4 or 5 setae (Figure 38); Median volsella triangular, tapering towards apex, with both simple setae and about 4 to 6 spatulate setae distally (Figures 38, 41), simple setae almost reaching tip of inferior volsella; Palpomeres 3 and 4 lacking patches of microtrichia (Figure 37) P. curvispinus sp. nov.

\section{Pupal exuviae}

1. Thoracic horn present; Pearl row on wing sheath present or absent, when present, pearl row is usually short, stopping well before nose; Hump on suture of thorax present or absent; when hump is present, granulations are dense other Paratanytarsus species [Not keyed]

- Thoracic horn absent; Pearl row present, either very long or short (Figures 19-22); Hump on thoracic suture present, usually distinct (Figures 15, 17-18), if indistinct, hump is defined by a cluster of granulations (Figure 16)

2. Pearl row very long, almost reaching the nose (Figure 19); Median patch on tergite VI consists of short spines (Figure 27); Thoracic hump large, smoothly rounded, domed, with minute faint granulations, only anterior part of suture with dense granulations (Figure 15); D5 on tergite III taeniate (Figure 24); Apical margin of anal lobe straight (Figure 32) P. corsicanus sp. nov.

Pearl row short, stops well before the nose (Figures 20-22); Median patch on tergite VI with dark points or bearing faint short spines (Figures 29-31); Thoracic hump and suture granulations not as described above (Figures 16-18); D5 on tergite III taeniate or bristle-like; Apical margin of anal lobe rounded (Figure 33) (bituberculatuscomplex)

. .3

3. Thoracic suture without anterior and posterior granulations, hump weakly domed, indistinct, indicated by a cluster of faint granulations (Figure 16)

P. bituberculatus (Edwards 1929)

Thoracic suture with anterior and posterior granulations, hump distinct, pointed or strongly granulose (Figures 17, 18)

4

4. Hump on thoracic suture bent backwards and pointed apically (Figure 17); Median patch on tergite VI composed of dark points (Figure 30); D5 on tergite III bristle-like P. curvispinus sp. nov.

- Hump on thoracic suture almost indistinct, strongly granulose (Figure 18); Median patch on tergite VI composed of dark spines (Figure 31); D5 on tergite III taeniate P. oconnori sp. nov.

\section{ACKNOWLEDGMENTS}

The authors are grateful to Dr J. Giudicelli, Dr B. Roché (†), Dr A. Orsini and Dr C. Mori for their hospitality in Corté City who provided facilities to the senior author in Corsica at the meeting of the "French Association of Limnology" in July 1997. We are also indebted to Prof. B. Rossaro for providing specimens of $P$. bituberculatus from Italy. 


\section{REFERENCES}

Delettre YR. 2001. An annotated checklist of Chironomidae (Diptera) trapped in Brittany (France) since 1975. Annales de Limnologie 37: 143-149.

Ekrem T. 2001. A review of Afrotropical Tanytarsus van der Wulp (Diptera: Chironomidae). Tijdschrift voor Entomologie 144: 5-40.

Ekrem T. 2002. A review of selected south- and east Asian Tanytarsus v. d. Wulp (Diptera: Chironomidae). Hydrobiologia 474: 1-39.

Furon R. 1950. Les grandes lignes de la Paléogéographie de la Méditerranée (Tertiaire et Quaternaire). Vie et Milieu 1: 131162.

Furon R. 1972. Eléments de Paléoclimatologie. Vuibert, Paris, 210 pp, 24 figs.

Giłka W. 2009. Order Diptera, family Chironomidae Tribe Tanytarsini. Arthropod Fauna of the UAE 2: 667-682.

Giłka W. 2011. Ochotkowate - Chironomidae, plemię: Tanytarsini, postaci dorosłe, samce. Klucze do oznaczania owadów Polski. [Non-biting midges - Chironomidae, tribe Tanytarsini, adult males. Keys for the Identification of Polish Insects]. Nr 177 serii kluczy. Część XXVIII, Muchówki - Diptera, zeszyt 14b. Polskie Towarzystwo Entomologiczne. Biologica Silesiae, Wrocław, 95 str. [in Polish]

Giłka W, Paasivirta L. 2008. On the systematics of the tribe Tanytarsini (Diptera: Chironomidae) - three new species from Finland. Entomologica Fennica 19: 41-48.

Giudicelli J. 1975. Analyse de la l'endémisme dans la faune des eaux courantes de la Corse. Ecologia Mediterranea 1: 133-147.

Goetghebuer M. 1921. Chironomides de Belgique et spécialement de la zone des Flandres. Mémoires du Musée Royal d'Histoire Naturelle de Belgique 8 (Fascicule 4, Mémoire 31): 1-208 + [2] p.

Johannsen OA. 1905. Aquatic nematocerous Diptera II Chironomidae. Pp 76-330, 333-352, pls 16-37. In Needham, J. G., Morton, K. J. and Johannsen, O. A. (eds) May flies and midges of New York. Bulletin of the New York State Museum 86: $1-352$.

Kieffer JJ. 1909. Diagnoses de nouveaux chironomides d'Allemagne. Bulletin de la Société d'Histoire Naturelle de Metz 26: 37-56.

Langton PH. 1991. A key to pupal exuviae of West Palaearctic Chironomidae. Privately published. Huntingdon, England, 386 pp.

Langton PH, Pinder LCV. 2007. Keys to the adult male Chironomidae of Britain and Ireland. Volume 1 (Pp: 1-239) and volume 2 (Pp: 1-168). Freshwater Biological Association, Scientific Publication No. 64.

Langton PH, Visser H. 2003. Chironomidae exuviae. A key to pupal exuviae of the west Palaearctic Region. Amsterdam: Biodiversity Center of ETI. CD-Rom.

Langton PH, Cranston PS, Armitage P. 1988. The parthenogenetic midge of water supply systems, Paratanytarsus grimmii (Schneider) (Diptera: Chironomidae). Bulletin of Entomological Research 78: 317-328.

Laville H, Serra-Tosio B. 1996. Additions et corrections à l'inventaire des Chironomidés (Diptera) de France depuis 1990. Annales de Limnologie 32: 115-121.

Laville H, Langton PH. 2002. The lotic Chironomidae (Diptera) of
Corsica (France). Annales de Limnologie 38(1): 53-64.

Moubayed-Breil J. 2007. Non-biting midges from Continental France: new records, faunal and biogeographical outline (Diptera, Chironomidae). Ephemera 9(1): 17-32.

Palmén E. 1960. Paratanytarsus-Arten (Dipt., Chironomidae) aus dem $\beta$-mesohalinen und oligohalinen Brackwasser der Finnischen Meerbusens. Annales Entomologici Fennici 26: 280-291.

Reiss F. 1968. Ökologische und systematische Untersuchungen an Chironomiden (Diptera) des Bodensees. Ein Beitrag zur lakustrischen Chironomidenfauna des nördlichen Alpenvorlandes. Archiv für Hydrobiologie 64(2/3): 176-323.

Reiss F, Säwedal L. 1981. Keys to males and pupae of the Palaearctic (excl. Japan) Paratanytarsus Thienemann \& Bause, 1913, n. comb., with descriptions of three new species (Diptera: Chironomidae). Entomologica Scandinavica Supplement 15: 73-104.

Sæther OA. 1980. Glossary of chironomid morphology terminology (Diptera: Chironomidae). Entomologica Scandinavica Supplement 14: 1-51.

Sæther OA, Spies M. 2011. Chironomidae. In: Fauna Europaea Service (ed.). Fauna Europaea, internet database at http://www. faunaeur.org [visited April 2011].

Säwedal L, Langton PH. 1977. Redescription of Paratanytarsus tenellulus (Goetghebuer, 1921) (Diptera: Chironomidae). Entomologica Scandinavica 8: 167-171.

Shilova AI. 1976. Khironomidy Rybinskogo Vodokhranilishcha. Izvestiya Academii Nauk SSSR 1976, 249 pp.

Schneider A. 1885. Chironomus Grimmii und seine Parthenogenesis. Zoologische Beiträge 1: 301-302.

Stur E, Ekrem T. 2006. A revision of West Palaearctic species of the Micropsectra atrofasciata species group (Diptera: Chironomidae). Zoological Journal of the Linnean Society 146: 165-225.

Thienemann A. 1951. Tanytarsus-Studien II. Die Subsectio Paratanytarsus. AufGrund der nachgelassenen Papiere Friedrich Wilh. Carl Krüger's. Archiv für Hydrobiologie Supplement 18: 595-632. 